\title{
䣄学通极
}

\section{中国黄土综合古气候指标的非线性反演 *}

\author{
吴乃琴 吕厚远 郭正堂
}

(中国科学院地质研究所, 北京 100029)

\section{关钺词 黄土 气候指标 反演}

迄今, 人们只是利用气候替代性指标与单个气候因子的线性关系估算古气候的 ${ }^{[1]}$, 或者 利用趋势面分析方法, 建立了气候替代性指标与两个气候因子的非线性方程, 而没能够真正用 于古气候参数的估算 ${ }^{[2]}$. 地质记录中物理的、化学的、生物的气候替代性指标是互相影响的. 每一种气候替代性指标又会同时受到多种气候因子的控制. 如果能找到它们之间在多种气候 因子同时控制下的气候平衡点, 就有希望解决利用不同气候指标单独恢复古气候时可能出现 的矛盾. 本文试图做这方面的努力:首先建立现代沉积环境中物理的、化学的、生物的气候指 标同时与多个气候参数之间的非线性方程, 只要方程数大于 (或等于)变量 (气候因子) 数, 在给 定的初值条件下, 代入相应的古气候指标, 求解方程组, 可以同时得到一组气候因子的解, 从而 完成综合古气候指标的非线性反演.

\section{1 材料与方法}

本文采用的黄土高原的现代表层土壤样品的磁化率值 63 个 ${ }^{[3]}$, 全氧化铁样品 12 个(其中 11 个样品采用文献 [4]的资料), 蜗牛样品 28 个, 分别作为物理、化学和生物的气候指标. 对 洛川坡头黄土剖面 S1 以上的地层间隔 $10 \mathrm{~cm}$ 采样, 同时做磁化率、全氧化铁和蜗牛化石分析. 其中表层土壤和黄土剖面中蜗牛化石的采样利用第析法(篣孔 $0.5 \mathrm{~mm}$ ) 获取了包括大量小个 体蜗牛的化石组合.

利用现代表层土壤点的年均温度和年均降水量资料建立与气候指标的多项式回归方程:

$$
\begin{aligned}
f_{1}= & 299.8386-333.1865 X+2.555124 Y- \\
& 43.92084 X^{2}+1.715249 X Y-0.0121515 Y^{2}, \\
C= & 69.42 \%, F=29.06, F_{0.01(5,22)}=3.99 ; \\
f_{2}= & 649.0248-29.42385 X-0.5627315 Y+2.736182 X^{2}- \\
& 0.04135922 X Y+0.0012086 Y^{2}, \\
C= & 91.46 \%, F=12.86, F_{0.01(5,6)}=8.75 ; \\
f_{3}= & 14.20996-0.8342041 X+0.603137 Y+0.957504 X^{2}+0.041368 X Y- \\
& 0.0024335 Y^{2}+0.036026 X^{3}-0.0036754 X^{2} Y-0.0000184 \times Y^{2}+ \\
& 0.000002336 Y^{3},
\end{aligned}
$$

1995-10-24 收稿, 1995-12-25 收修改稿

* 国家自然科学基金资助项目 


$$
C=76.64 \%, F=19.33, F_{0.01(9,53)}=2.75,
$$

式中 $f_{1}$ 为蜗牛 (Vallonia sp.) 的百分含量, $f_{2}$ 为全氧化铁的百分含量 (为了保证在解方程组 时, 全氧化铁与磁化率有相同量级的精度, 对表土和地层的全氧化铁都乘 100$), f_{3}$ 为磁化率值 $\left(10^{-8} \mathrm{SI}\right), X$ 为年均温度 $\left({ }^{\circ} \mathrm{C}\right), Y$ 为年均降水量 $(\mathrm{mm}), C$ 为拟合度. 经检验 3 个方程都非常 显著. 将每个黄土样品的 Vallonia sp. 、全氧化铁的含量和磁化率的值分别代入上述方程, 本 文采用下降法解非线性方程组: 设非线性方程组 $f_{i}\left(X_{1}, X_{2}, \cdots, X_{n}\right)=0 \quad(i=1,2, \cdots, n)$, 求平方和函数 $F\left(X_{1}, X_{2}, \cdots, X_{n}\right)=\sum_{i=1}^{n} f_{i}^{2}\left(X_{1}, X_{2}, \cdots, X_{n}\right)$ 的一实零点. 若 $F\left(\bar{X}_{1}, \bar{X}_{2}\right.$, $\left.\cdots, \bar{X}_{n}\right)<\varepsilon$, 则 $\bar{X}_{1}, \bar{X}_{2}, \cdots, \bar{X}_{n}$ 是方程组满足精度要求的一组解. 计算中采用洛川现代的年 均温 $9.2^{2} \mathrm{C}$ 、年均降水 $620 \mathrm{~mm}$ 作为给定的初始试探值, $\varepsilon$ 选为 0.0001 , 精度控制在 $1 \%$.

\section{2 结果与讨论}

图 1 为洛川坡头黄土剖面 S1 层位以上的 Vallonia $\mathrm{sp}$. 、全氧化 铁和磁化率曲线以及通过这 3 种 古气候指标反演的年均温度、年 均降水量曲线. 可以看出 3 种古 气候指标曲线在剖面中的峰谷变 化是存在一定相位差的, 反演后 的年均温度、年均降水量在一定 的误差之内同时满足了 3 种气候 指标与温度、降水量的非线性关 系, 或者说找出了三者的相容解, 古气候曲线综合了 3 种气候指标
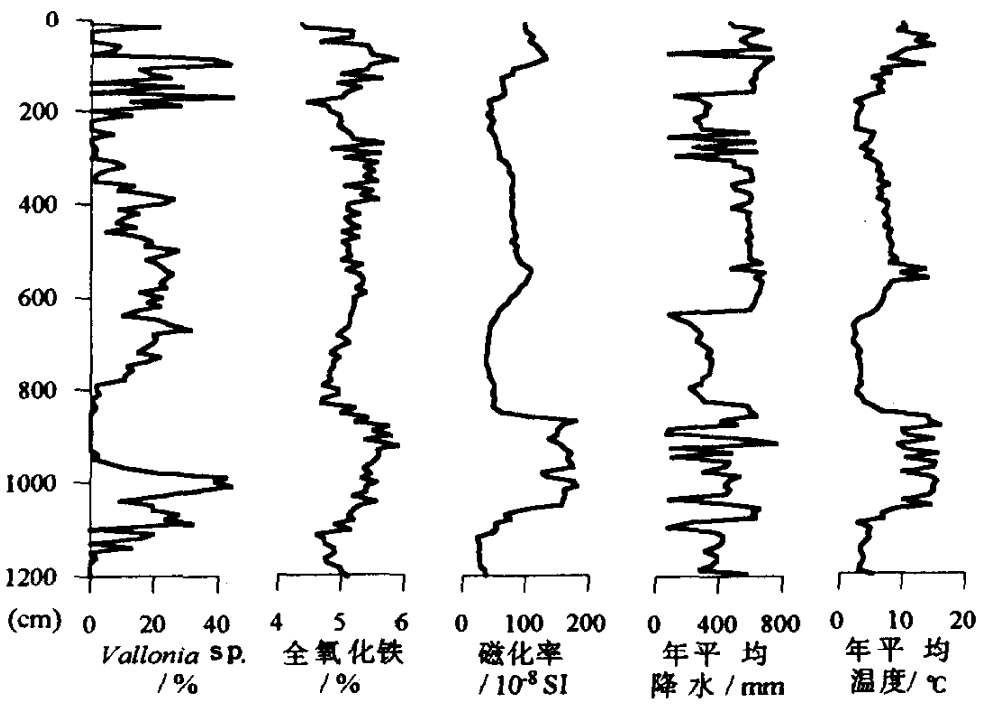

图 1 洛川黄土剖面古气候指标及所反演的温度、降水量曲线 的变化特点. 求解非线性方程组关键是综合考虑了各种古气候指标同时受温度、降水量的影 响, 而不象一般转换函数割裂了温度和降水量的作用. 从理论上讲, 这种综合古气候指标的非 线性反演更为合理. 如果上述 3 个非线性方程有充分的代表性, 古气候参数的计算相对更加 客观. 由于现代表层土壤的蜗牛样品和全氧化铁样品数量较少, 还难以估计反演后的古温度、 古降水量的误差范围. 本文旨在探讨利用综合气候指标进行古气候非线性反演的可行性. 这 种方法还可以推广到同时考虑 3 个(或 3 个以上) 的气候(或环境)因子, 求解三元 (或三元以 上)的非线性方程组.

\section{参考文 献}

1 Imbrie J, Kipp N G. A new micropaleontological method for quantitative paleoclimatology: application to a Late Pleistocene caribbean core. In: Turekian K K ed. The Cenozoic Glacial Ages, Yale Univ, 1971. 71 181

2 Bartlein P J, Prentice I, Webb III T. Climatic response surfaces from pollen data for some Eastern North American Taxt. Journal of Biogeography, 1986, 13: 35 57

3 吕厚远, 韩家惁, 吴乃琴等. 中国现代土壤磁化率分析及其古气候意义, 中国科学, B 辑, 1994, 24(12): $1290 \sim 1297$

4 张宗祜, 魏明建. 黄土中全氧化铁与气候指标的定量关系. 科学通报, 1995, 40(13): $1219 \sim 1221$. 